(1) Semantics \& Pragmatics Volume 3, Article 5: 1-15, 2010

G doi: $10.3765 / \mathrm{sp} .3 .5$

\title{
Embedded Implicatures?
}

\section{Remarks on the debate between globalist and localist theories}

\author{
Michela Ippolito \\ University of Toronto
}

Received 2009-10-24 / Revised 2009-12-28 / Published 2010-03-24

\begin{abstract}
Geurts \& Pouscoulous (2009) present experimental evidence that embedded implicatures are not systematically available and conclude that localist theories of implicatures cannot be maintained. I argue that this conclusion can be strengthened by showing that their findings cannot be reconciled with a localist theory even when the latter is supplemented with a formal way to predict when an embedded implicature will be preferred, as suggested in Chierchia, Fox \& Spector 2008.
\end{abstract}

Keywords: implicatures, scalar implicatures, embedded implicatures, conversational implicature, local implicature, experimental pragmatics, neg-raising verbs

\section{Introduction}

Geurts \& Pouscoulous (2009) present some interesting experimental data pointing against a localist view of scalar implicatures according to which scalar implicatures are systematically generated in embedded as well as in non-embedded positions.

One case that typically is said to trigger an embedded implicature is the case of a clause embedded under an attitude verb such as think or believe, as in (1).

(1) John thinks that Fred heard some of Verdi's operas.

The implicature that (1) generates - the localist maintains - is that John thinks that Fred heard some but not all of Verdi's operas. Assuming a localist view according to which implicatures are triggered by means of a silent exhaustive operator $\mathbf{O}$ as in Chierchia et al. 2008, the embedded implicature

(C)2010 Michela Ippolito

This is an open-access article distributed under the terms of a Creative Commons NonCommercial License (creativecommons.org/licenses/by-nc/3.o). 
in (1) is triggered when $\mathbf{O}$ adjoins the embedded clause as shown in (2). ${ }^{1}$ This gives rise to the meaning in (3).

(2) John thinks that $\mathbf{O}$ (Fred heard some of Verdi's operas)

(3) John thinks that Fred heard some of Verdi's operas and John thinks that Fred didn't hear all of Verdi's operas

According to the globalist view, embedded implicatures such as (3) cannot be generated and (1) can only conversationally implicate that John doesn't think that Fred heard all of Verdi's operas. Suppose that John is knowledgeable about whether Fred heard all of Verdi's operas or not. Then, from the weak implicature that John doesn't believe that Fred heard all of Verdi's operas we can infer that John believes Fred didn't hear all of Verdi's operas. This is what Sauerland (2004) calls the "epistemic step". The result looks like the embedded implicature that the localist generates by embedding the exhaustive operator $\mathbf{O}$, but in fact is just a global implicature strengthened by means of some assumptions about John's epistemic state. ${ }^{2}$

Geurts and Pouscoulous conclude that, on the basis of their findings, the localist position is untenable. Here I will discuss whether their findings can in principle be reconciled with a localist theory once the latter is supplemented with a mechanism for predicting when a given reading will be preferred or dispreferred. As a paradigmatic case, I will consider the localist theory defended by Chierchia et al. (2008). My conclusion will support Geurts and Pouscoulous's: even when supplemented with a mechanism for determining when an embedded implicature will be preferred, the localist predictions are incompatible with Geurts and Pouscoulous's findings.

Furthermore, I will consider the class of Neg-raising (NR) verbs (Horn 1978) and argue that a localist theory makes predictions which again are incompatible with Geurts and Pouscoulous's experimental findings. I will then sketch a way in which a globalist theory might in principle be able to explain the experimental differences we find among the NR predicates included in Geurts and Pouscoulous's questionnaires. However, further experimental research is needed in order to ascertain whether the globalist line of argument suggested here works when extended to other NR predicates.

1 That local implicatures exist has been advocated by several people, even though the idea has been implemented differently in different proposals. See for example Bach 1994, Carston 1988, Chierchia 2004, Fox 2006, Levinson 1983, Levinson 2000, Recanati 2003, among others.

2 Following Grice (1975), advocates of a globalist theory of implicatures include Gadzar (1979), Geurts (2009), Horn (1972, 1989), King \& Stanley (2006), among many others. 
Embedded Implicatures?

\section{Experiments and results}

To test whether the predictions made by the local view of implicatures are correct, Geurts and Pouscoulous looked at different types of embeddings. In their first experiment, they considered complex sentences where the scalar item some is embedded in the nuclear scope of the universal quantifier all; under a modal verb with a universal force; in the complement of think; and finally in the complement of want. They compared the results they obtained in these cases with the rate of implicatures drawn in unembedded clauses and found that, while scalar implicatures were accepted in the majority of simple (unembedded) cases, the acceptance rate was much lower in the complex conditions (with differences among conditions; see section 3.1 below). The experiment used an inference task in which participants were shown a sentence containing a scalar expression (e.g. some) and were asked whether they would infer that the corresponding sentence with the stronger scalar expression (e.g. all) was false. In a subsequent experiment, the authors compared the rate of local implicatures found using the inference task with the rate of local implicatures found using a verification task in which participants where shown a sentence containing a scalar expression and were asked to decide whether that sentence correctly described a picture that they were shown. The result of the latter experiment when applied to unembedded clauses showed that the inference paradigm yields higher rates of scalar implicatures than the verification paradigm, and therefore that the verification task is a more reliable way to find out the rate at which people actually draw scalar implicatures. When applied to the question of whether local implicatures are drawn in embedded clauses, the verification task performed by Geurts and Pouscoulous "completely failed to yield the local SIs predicted by mainstream conventionalism" (Geurts \& Pouscoulous 2009). In particular, the authors tested scalar items (here, some) embedded in downward-entailing (DE) contexts (i.e. Not all the squares are connected with some of the circles); scalar items embedded in upward-embedding (UE) contexts (i.e. All the squares are connected with some of the circles); and finally, scalar items embedded in non-monotonic (NM) contexts (i.e. There are exactly two squares that are connected with some of the circles).

In the next section, taking Chierchia et al. 2008 to be a paradigmatic example of a localist theory, I will spell out in more detail how this theory works and I will consider the consequences of Geurts and Pouscoulous's experimental results, particularly with respect to the issue of the frequency with which embedded implicatures are drawn. 
Michela Ippolito

\section{Discussion}

Geurts and Pouscoulous's experimental results are not per se a knockdown argument against embedded implicatures. The localist might object that Geurts and Pouscoulous's experimental results do not show that embedded (or local) implicatures are impossible but only that they are not generally available, and this is at least consistent with one possible localist view: that is, that since they seem to be triggered in special circumstances, embedded implicatures must be possible, even though they are not generally available. Chierchia et al. (2008) have recently discussed some of the circumstances where embedded implicatures are triggered. The examples in (4) through (6) illustrate some of these circumstances.

(4) If you take salad or dessert, you pay $\$ 20$; but if you take both there is a surcharge.

(5) Exactly two students wrote a paper or ran an experiment. The others either did both or made a class presentation.

Mary solved some or all of the problems.

Take (4). Chierchia et al. (2008) argue that, while implicatures are not normally triggered in the antecedent of conditionals (a DE environment), the continuation in (4) forces an exclusive interpretation of or in the antecedent (that is an interpretation of the antecedent strengthened with the scalar implicature "but not both") as the only way to guarantee a coherent interpretation for the discourse. Embedding the exhautive operator in the antecedent guarantees that such an interpretation is generated. ${ }^{3}$

Someone might initially object to Chierchia et al.'s (2008) argument that, if embedded and non-embedded implicatures are generated by the same mechanism-in this case the exhaustive operator $\mathbf{O}$-then you would not expect local implicatures to be confined to this very special set of cases. The fact that local implicatures seem to be confined to a very narrow set of cases, and that occurrences of scalar items (such as some or or) in embedded positions do not normally trigger local implicatures raises the suspicion that the "effect"

3 Similarly for (5) and (6). In (5), the continuation is argued to force the embedded implicature giving rise to the interpretation according to which 'exactly two students wrote a paper or ran an experiment but didn't do both'. The continuation in (6) is also argued to force the embedded implicature so that as a result the interpretation of the sentence will be that either Mary solved some but not all of the problems or she solved all of them. 
of local implicatures is actually due to a different mechanism, and that these are not implicatures after all. ${ }^{4}$

To address the issue of the frequency of embedded implicatures (why embedded implicatures are much less frequent than global implicatures), Chierchia et al. (2008) have suggested that there is a preference for the strongest possible interpretation among the possible readings of a sentence, and that this might account for why having the exhaustive operator $\mathbf{O}$ in the scope of a DE operator is a dispreferred option since it gives rise to an interpretation weaker than the one obtained without $\mathbf{O}$. The authors consider two versions of the "strongest meaning hypothesis" (SMH), as shown in (7) and (8), both from Chierchia et al. 2008.

(7) SMHı:

Let $\varphi$ be a certain logical form. Let $\varphi$ 's competitors be all the LFs that differ from $\varphi$ only with respect to where the exhaustivity operator occur. Then, everything else being equal, $\varphi$ is dispreferred if one of its competitors is stronger than $\varphi$.

(8) SMH2:

Let $S$ be a sentence of the form $[s \ldots \mathrm{O}(\mathrm{X}) \ldots]$. Let $S^{\prime}$ be the sentence of the form $\left[s^{\prime} \ldots X \ldots\right]$, i.e. the one that is derived from $S$ by replacing $\mathrm{O}(\mathrm{X})$ by $\mathrm{X}$, i.e. by eliminating this particular occurrence of $\mathrm{O}$. Then everything else being equal, $S^{\prime}$ is preferred to $S$ if $S^{\prime}$ is logically stronger than $S$.

According to SMH1, given a certain logical form, all LFs differing in where the exhaustivity operator occurs will compete with each other and the strongest $\mathrm{LF}$ will be preferred. According to $\mathrm{SMH}$, alternative LFs differing in the placement of the exhaustive operator do not compete with each other but only with the LF without the operator. Taking Chierchia et al.'s (2008) theory as the paradigmatic localist theory, the question that arises is whether the localist theory sketched above supplemented with either SMH1 or SMH2 can be reconciled with Geurts and Pouscoulous's experimental results.

4 This might explain why, while focal stress is often needed to bring out the embedded implicature interpretation, focal stress is not needed to bring out the non-local implicature interpretation. Chierchia et al. (2008) attribute the fact that focal stress helps the embedded implicature reading of the sentences they consider to the nature of the mechanism they appeal to, i.e. covert exhaustification, which is triggered by focus. However covert exhaustification is also supposed to be responsible for the non-local implicature raising the question why focal stress is a relevant factor in the explanation of one type of implicature but not in the explanation of the other. 
Consider the predictions made by either version of SMH for sentences where the scalar item is embedded under the epistemic predicate be certain.

(9) John is certain that Fred heard some of Verdi's operas.

a. John is certain that $\mathbf{O}$ (Fred heard some of Verdi's operas)

b. O(John is certain that Fred heard some of Verdi's operas)

The configuration of the operator $\mathbf{O}$ in (9a) triggers the local implicature that John is certain that Fred did not hear all of Verdi's operas. (9b), on the other hand, triggers the implicature that John is not certain that Fred heard all of Verdi's operas. Consider SMH1 first. Let us assume that $\alpha$ is certain that $\varphi$ means that $\alpha$ has a justified belief that $\varphi$ is true. ${ }^{5}$ The assertoric content of (9) strengthened by the implicature in (9a) gives rise to a meaning stronger than the meaning obtained by strengthening (9)'s assertion with the implicature in (9b). If in all of John's doxastic worlds it is true that Fred heard some but not all of Verdi's operas (and if John is justified in having this belief), then it is not the case that in all of John's doxastic worlds Fred heard all of Verdi's operas (and it is not the case that John is justified in believing that Fred heard them all). This entailment is asymmetric. Therefore, SMH1 predicts that the interpretation in (9a) should be the preferred one. However, assuming that Geurts and Pouscoulous's findings can be extended to predicates such as be certain, they show that the embedded implicature in (9a) is clearly not the preferred interpretation.

Suppose we assume SMH2 instead of SMH1. Because both LFs with the exhaustive operator convey interpretations stronger than the one conveyed by the LF without the operator, the proposal predicts that both (9a) and (9b) should be equally available. But we have already seen that Geurts and Pouscoulous's results show that this is not the case: (9a) is dispreferred. Appealing to independent considerations like the lack of plausibility for the reading in (9a), in order to explain why it is rare is a dubious move. In Geurts and Pouscoulous's experiments, the context plays no role. Therefore, we expect that the most salient reading (the reading preferred by the participants in the experiment) will be the one selected by the SMH, but we saw that this is not the case.

$5 \mathrm{I}$ am not claiming that this is all there is to say about what be certain means. All I am assuming here is that saying that $\alpha$ is certain that $\varphi$ entails that $\alpha$ believes $\varphi$ and has some justification for believing $\varphi$. 
Embedded Implicatures?

Similar considerations apply to modal verbs like wish:

(10) John wishes that Fred would try some of the cookies.

a. John wishes that $\mathbf{O}$ (Fred would try some of the cookies)

b. O(John wishes that Fred would try some of the cookies)

The configuration in (10a) triggers the embedded implicature that John wishes that Fred would not try all of the cookies. In (1ob), on the other hand, the implicature is that John doesn't wish that Fred would try all of the cookies. Consider first the prediction made by SMH1. Just like in the previous example, (10)'s assertion supplemented with the embedded implicature in (10a) gives rise to a meaning stronger than the meaning obtained by incrementing the same assertion with the implicature in (1ob): if John's desire-worlds are all worlds where Fred tries some but not all of the cookies, then it is not the case that all of John's desire-worlds are worlds where Fred tries all of the cookies. However, the reverse does not hold: the assertion together with (1ob) is compatible with a state of affairs where in some of John's desireworlds Fred tries all of the cookies, a possibility ruled out by the implicature in (10a). Therefore, (10a) is predicted to be the preferred reading of the sentence in (10) by SMH1. One of the conditions that Geurts and Pouscoulous tested in one of their experiments was embedding of a scalar item under want and they found that the embedded implicature reading was not the preferred interpretation of the sentence. If their results can be extended to any volitional verb, including wish, they show that the prediction made by SMH1 is not correct. Similarly for SMH2: in this case, both (10a) and (1ob) are predicted to deliver meanings stronger than the meaning obtained without $\mathbf{O}$ and so the two strengthened interpretations are incorrectly predicted to be equally available. This is so unless some independent contextual consideration rules out (10a), but as we observed above the context plays no role in Geurts and Pouscoulous's experiment and therefore we do not expect it to be a factor affecting the subjects's judgments.

In conclusion, even when supplemented with a formal mechanism for predicting when an embedded implicature will be preferred or dispreferred, Chierchia et al.'s (2008) localist theory fails to account for the fact that embedded implicatures are systematically dispreferred. Appealing to contextual/plausibility considerations in order to override the outcome of the theory is problematic since in Geurts and Pouscoulous's experiments judgments were elicited out-of-context. 
In the next section, I will look at the exceptional behavior of the verb believe, for which Geurts and Pouscoulous found a higher acceptance rate for the embedded implicature than in any other complex condition. Even though the exceptional behavior of believe initially appears to support a localist theory, I will conclude that it actually constitutes another challenge for it.

\subsection{Believe and other Neg-raising verbs}

Consider (11), a variant of Geurts and Pouscoulous's original sentence. ${ }^{6}$ (11a) and (11b) give rise to the embedded implicature reading and the global implicature reading, respectively.

(11) John believes that Fred tried some of the cookies.

a. John believes that $\mathbf{O}$ (Fred tried some of the cookies)

b. $\mathbf{O}$ (John believes that Fred tried some of the cookies)

According to Horn (1978) and others, believe is a Neg-raising (NR) verb: a normal utterance of John doesn't believe Mary lied implies that John believes that Mary didn't lie. Similarly, (11b) will imply that John believes that Fred did not try all of the cookies. Therefore, both configurations in (11a) and (11b) give rise to the same implicature and, according to both SMH1 and SMH2, since both available interpretations are equivalent and are stronger than the LF without $\mathbf{O}$, they should be equally available. Indeed, Geurts and Pouscoulous found a relatively high rate of acceptance of the embedded implicature in the believe/think condition (even though, as we saw, it wasn't the preferred interpretation), and they acknowledge the possibility that this "elevated level of positive responses (57.5\%) wasn't merely an artifact" of the inference model (Geurts \& Pouscoulous 2009).

The problem is that a similar prediction is made by Chierchia et al. (2008) with respect to want.

(12) John wants Fred to try some of the cookies.

a. John wants $\mathbf{O}$ (Fred to try some of the cookies)

b. $\mathbf{O}$ (John wants Fred to try some of the cookies)

According to the classification in Horn 1978, want is also NR. It follows that Chierchia et al.'s (2008) localist theory predicts that both (12a) and (12b) should be equally available. However, the rate of acceptance of the embedded

6 Geurts and Pouscoulous's sentence was given in (1). (1) is a translation of the French sentence actually used in the experiment. 
Embedded Implicatures?

implicature with the modal verb want was low (32\%), lower than what they found in the believe case. The embedded implicature reading is dispreferred, and nothing in how the exhaustive operator $\mathbf{O}$ or SMH work seems to explain why the embedded implicature is more frequently accepted with believe than with want.

Geurts and Pouscoulous, following the lines of van Rooij \& Schulz 2004 and Russell 2006, sketch a globalist account for why believe shows a higher acceptance of the embedded implicature: (i) the sentence Bob believes that Anna ate some of the cookies generates the global implicature that Bob doesn't believe that Anna ate all of the cookies; (ii) assuming that Bob has an opinion about whether Anna ate all of the cookies or not, it follows that Bob believes that Anna did not eat all of the cookies. Now, in their paper defending a localist view of implicatures, Gajewski \& Sharvit (2009) criticize this type of globalist account by arguing that appealing to the disjunctive proposition "either Bob believes that Anna ate all of the cookies or he believes that she didn't" in the reasoning above is only plausible because believe is a NR verb and as such it carries the presupposition that either $\alpha$ believes that $\varphi$ or $\alpha$ believes that it is not the case that $\varphi$ (as argued in Gajewski 2005). In other words, according to Gajewski and Sharvit, the globalist account only appears to work because the predicate is NR and the disjunctive proposition crucial to the globalist explanation is actually presupposed by the verb. But if this were correct, then all NR verbs would trigger an embedded implicature since they all presuppose the relevant disjunctive proposition. But we just saw that this is not so: the experimental results reported in Geurts and Pouscoulous show that local implicatures with want are relatively rare, despite want being a NR verb. A short digression on NR verbs is in order here. I have assumed with Horn (1978) that want, like believe but unlike wish, is NR based on the observation that in (13) but not in (14) the first sentence implies the second.

(13) a. I don't want Mary to leave.

b. I want Mary not to leave.

(14) a. I don't wish to meet Mary.

b. I wish not to meet Mary.

However, Rooryck (1991) cites the following pair from Horn 1978 against the view that want/vouloir are NR verbs: while (15) supports the NR hypothesis, (16) does not. 
a. Je ne veux pas que vous sortiez.

"I don't want you to leave"

b. Je veux ques vous ne sortiez pas.

I want you not to leave"

(16)

a. Je ne voudrais pas être Dieu.

"I wouldn't want to be God"

b. Je voudrais ne past être Dieu.

"I would want not to be God"

Rooryck concludes that volitional verbs only appear to be NR but in fact they are not. An exhaustive discussion of this issue is beyond the scope of this paper. However, what is important in the context of the current discussion about embedded implicatures is to notice that even if volitional verbs are not $\mathrm{NR}$, it is still true that in cases such as (15) vouloir behaves like a NR verb in that the two sentences are judged to be synonymous, just like originally observed by Horn. Just like in (15), the English rendition of the implicature in (12b) (i.e. John doesn't want Fred to try all of the cookies) is also judged to have a NR interpretation, and so does the French translation with vouloir. ${ }^{7}$ Therefore, since the logical form in (12b) receives a NR interpretation, it is expected to pattern like non-volitional NR verbs such as believe with respect to the computation of the embedded implicatures, and the experimental results show it does not.

Going back to the main discussion, obviously the globalist needs to explain the asymmetry between want and believe too. In principle we should be able to run the reasoning sketched by Geurts and Pouscoulous for believe with want: (i) (12) generates the implicature that John doesn't want Fred to try all of the cookies; (ii) let us assume that John has a definite desire about Fred's trying all of the cookies, that is, that either John wants Fred to try all of the cookies or he wants Fred not to try all of the cookies; (iii) it follows that John wants Fred not to try all of the cookies. The crucial step is (ii). What "blocks" (ii) in the want case but not in the believe case?

We saw that dismissing the globalist account by appealing to the presuppositional nature of this disjunctive proposition is not going to work. According to the Russellian line followed by Geurts and Pouscoulous, an assumption like "either John wants Fred to eat all of the cookies or John

7 Thanks to Annick Morin for providing the French sentence Je (ne) veux pas que Marie mange tous les biscuits and for her judgment. 
Embedded Implicatures?

wants Fred not to eat all of the cookies" is purely contextual and as such it will be part of the common ground in some contexts but not in others. Whenever the context grants this assumption, the strengthening of the global implicature happens, giving rise to an embedded implicature effect without an actual embedded implicature. If this is correct, then the reason why subjects assented to the local implicature less frequently in the want case than in the believe case must have to do with how likely they felt they could make the relevant disjunctive assumption. In particular, it must be the case that, in the absence of any context, subjects felt that the assumption in (17a) was less likely to be true than the assumption in (17b).

(17) a. Either John wants Fred to try all of the cookies or John wants Fred not to try all of the cookies.

b. Either Bob believes that Anna ate all of the cookies or he believes that she didn't.

If it is the case that, out of context, people are less likely to make the assumption in (17a) than the one in $(17 b)$, we expect that it should be much easier to trigger the apparent local implicature with want if the context allows one to do so. In the globalist theory, then, plausibility considerations such as the ones outlined above might be expected to distinguish among other NR verbs which the localist theory would predict pattern alike with respect to embedded implicatures. ${ }^{8}$

The localist too can appeal to the context (and Chierchia et al. (2008) leave this door open explicitly in their paper), but appealing to the context

8 One pair of predicates that might be interesting to test experimentally is the pair expect/ought to, as in John expects Mary to try some of the cookies and Mary ought to try some of the cookies. According to Horn 1978, both predicates are NR. The localist theory predicts that both should give rise to a high rate of acceptance of the embedded implicature ("John expects Mary not to try all of the cookies" and "Mary ought to not try all of the cookies", respectively), at least out of context. The globalist theory, on the other hand, would have to appeal to two different disjunctive propositions in order to strengthen the global implicature giving rise to an embedded implicature effect.

(18) a. Either John expects Mary to try all of the cookies or John expects Mary not to try all of the cookies.

b. Either Mary ought to try all of the cookies or Mary ought to not try all of the cookies.

At least out-of-context, it seems that (18a) would be easier to assume. If indeed (18a) is more plausible than $(18 \mathrm{~b})$, then the globalist theory predicts that the acceptance rate for the embedded implicature should be higher in the expect case than in the ought case. 
in this case is needed to systematically "correct" the predictions of the theory which are not supported by the experimental findings (recall that the preferred interpretation according to Chierchia et al.'s (2008) localist theory augmented with either version of the SMH is not the interpretation preferred by Geurts and Pouscoulous's subjects). Finally, we noticed that appealing to the context in order to override the outcome of the theory does not seem right in Geurts and Pouscoulous's experiments since in both the inferential and the verification tasks the subjects had to make their choice out-of-context. Since the context plays no role in Geurts and Pouscoulous's experiments, we expect the reading selected by the theory to surface undisturbed in people's judgments. The fact that the subjects's judgments did not agree with the predictions of the localist is therefore problematic.

\section{Conclusion}

The experimental results presented by Geurts and Pouscoulous are at odds with the predictions of the localist, in particular the localist theory advocated by Chierchia et al. (2008) The challenge for the localist is to explain why embedded implicatures are so infrequent. We focused on the believe and want conditions in Geurts and Pouscoulous's experiments. They found that the acceptance rate for the embedded implicature in the believe condition was not negligeable (even though the imbedded implicature reading was still not the preferred one). Since believe is a NR, we observed that the localist view advocated in Chierchia et al. 2008, together with either version of the strong meaning hypothesis (what we called SMH1 and SMH2), seems to account for the elevated rate of positive responses with believe. However, we also observed that the theory is unable to account for the very low acceptance rate with want, since want is also a NR verb.

When we considered non-NR verbs such as be certain and wish, which belong to the same category as believe and want respectively, we saw that Chierchia et al.'s (2008) localist view augmented with either SMH1 or SMH2 makes incorrect predictions about what should be the preferred interpretations when a scalar item occurs in an embedded clause. ${ }^{9}$

9 Whether be certain patterns like believe or not, the localist faces a problem. In the former case, the localist view faces a problem since be certain is not NR and the embedded implicature reading is predicted by his theory to be the preferred one. In the latter case (i.e. if be certain does not show the higher rate of acceptance of the embedded implicature found with believe), the problem is that the localist expects non-NR verbs like be certain to show high acceptance rate for the embedded implicature. 
Embedded Implicatures?

Furthermore, we noticed that the difference between want and believe reported in the experiment we are considering also undermines Gajewski and Sharvit's criticism of the globalist view. Gajewski and Sharvit have recently suggested that the globalist account in Russell (2006) seems to work for believe only because believe is NR (see above for details). But if that were true, since want is also NR we would expect the two to pattern in the same way, but they don't.

It seems hard to reconcile the rates of acceptance of the embedded implicatures found with epistemic and volitional verbs with the grammatical theory of embedded implicatures proposed by the localist. Appealing to the context in order to override the predictions of the theory is problematic since the context plays no role in Geurts and Pouscoulous' experiments. On the other hand, according to the global theory of implicatures, the appearance of an embedded implicature is due to the strengthening of the global implicature in a context where specific assumptions are taken to be part of the common ground: therefore, if the context plays no role (as in Geurts and Pouscoulous' experiments) or the relevant assumptions are not made, there will be no embedded implicature effect. In general, both globalist and localist theories must appeal to contextual considerations to make the correct predictions but, unlike in a localist theory, the role played by the context in a globalist theory is an essential component of the globalist theory itself. Indeed, we noted that plausibility considerations might be able to account for the contrast between want and believe reported by Geurts and Pouscoulous. However, more experimental evidence of the type provided by Geurts \& Pouscoulous (2009) must be collected in order to establish whether these considerations do play the explanatory role they are expected to play in a global theory of implicatures.

\section{References}

Bach, Kent. 1994. Conversational impliciture. Mind and Language 9(2). 124-162. doi:10.1111/j.1468-0017.1994.tboo220.x.

Carston, Robyn. 1988. Implicature, explicature and truth theoretic semantics. In Ruth Kempson (ed.), Mental representations: the interface between language and reality, 155-181. Cambridge \& New York: Cambridge University Press. 
Chierchia, Gennaro. 2004. Scalar implicatures, polarity phenomena, and the syntax/pragmatics interface. In Structures and beyond, 39-103. Oxford: Oxford University Press.

Chierchia, Gennaro, Danny Fox \& Benjamin Spector. 2008. The grammatical view of scalar implicatures and the relationship between semantics and pragmatics. In Claudia Maienborn, Klaus von Heusinger \& Paul Portner (eds.), Handbook of semantics, Mouton de Gruyter.

Fox, Danny. 2006. Free choice disjunction and the theory of scalar implicatures. http://web.mit.edu/linguistics/people/faculty/fox/free_choice.pdf.

Gadzar, Gerald. 1979. Pragmatics: Implicatures, presuppositions and logical form. New York: Academic Press.

Gajewski, Jon. 2005. Neg-raising: Polarity and presupposition: MIT dissertation. doi:1721.1/33696.

Gajewski, Jon \& Yael Sharvit. 2009. In defense of the grammatical approach to local implicatures. http://web2.uconn.edu/sharvit/ Gajewski-Sharvit-23nov2009.pdf.

Geurts, Bart. 2009. Scalar implicature and local pragmatics. Mind and Language 24(1). 51-79. doi:10.1111/j.1468-0017.2008.01353.x.

Geurts, Bart \& Nausicaa Pouscoulous. 2009. Embedded implicatures?!? Semantics and Pragmatics 2(4). 1-34. doi:10.3765/sp.2.4.

Grice, Paul. 1975. Logic and conversation. In Peter Cole \& Jerry Morgan (eds.), Syntax and semantics 3: Speech acts, 41-58. New York: Academic Press.

Horn, Laurence. 1972. On the semantic properties of logical operators in English: UCLA dissertation.

Horn, Laurence. 1978. Remarks on neg-raising. In Peter Cole (ed.), Syntax and semantics 9: Pragmatics, 129-220. New York: Academic Press.

Horn, Laurence. 1989. A natural history of negation. Chicago: The University of Chicago Press.

King, Jeff \& Jason Stanley. 2006. Semantics, pragmatics, and the role of semantic content. In Zoltan Szabó (ed.), Semantics vs. pragmatics, 111164. Oxford: Oxford University Press.

Levinson, Stephen. 1983. Pragmatics. Cambridge \& New York: Cambridge University Press.

Levinson, Stephen. 2000. Presumptive meanings: The theory of generalized conversational implicatures. Cambridge, MA: MIT Press.

Recanati, François. 2003. Embedded implicatures. Philosophical Perspectives 17(1). 299-332. doi:10.1111/j.1520-8583.2003.00012.x.

van Rooij, Robert \& Katrin Schulz. 2004. Exhaustive interpretation of complex 
Embedded Implicatures?

sentences. Journal of Logic, Language and Information 13(4). 491-519. doi:10.1007/s10849-004-2118-6.

Rooryck, Johan. 1991. Negative and factive islands revisited. Journal of Linguistics 28(2). 343-374. doi:10.1017/Soo22226700015255.

Russell, Benjamin. 2006. Against grammatical computation of scalar implicatures. Journal of Semantics 23(4). 361-382. doi:10.1093/jos/ffloo8.

Sauerland, Uli. 2004. Scalar implicatures in complex sentences. Linguistics and Philosophy 27(3). 367-391. doi:10.1023/B:LING.0oooo23378.71748.db.

Michela Ippolito

Department of Linguistics

University of Toronto

130 St. George Street

Toronto, ON M5S $3 \mathrm{H}_{1}$

Canada

michela.ippolito@utoronto.ca 